\title{
ARTICLE 3: CHARACTERIZATION OF THE STRESS-INDUCED GENE ZMCOI6.1 IN MAIZE: EXPRESSION AND PROMOTER SEQUENCES
}

\author{
THUY HA NGUYEN \\ Institute of Agricultural Genetics, Hanoi, Vietnam \\ JÖRG LEIPNER \\ Institute of Plant Sciences, Zỹrich, Switzerland \\ ORLENE GUERRA-PERAZA \\ University of Guelph, Ontario. Canada \\ PETER STAMP \\ Institute of Plant Sciences, Zỹrich, Switzerland
}

\begin{abstract}
Using cDNA subtraction technique, 18 cold stress responsive-genes were identified, among them a novel gene, ZmCOI6.1, whose function is still unknown. Analysis of the ZmCOI6.1 promoter sequence revealed several conserved stress-responsive cis-acting elements. Further expression characterization shows that ZmCOI6.1 is induced, in addition by cold, by other abiotic stresses such as drought and $\mathrm{NaCl}$ as well as by signalling molecules such as ABA and SA. The results indicate that ZmCOI6.1 is a general stress responsive gene. A possible regulation mechanism is presented where ZmCOI6.1 is alternatively spliced yielding two transcripts whose levels are changed upon different stress treatments. Furthermore the predicted ZmCOI6.1 amino acid sequence and its homologue show high similarity with proteins in rice and Arabidopsis suggesting that it belongs to a conserved protein in plants.
\end{abstract}

Cold-acclimation in plants involves multiple changes in morphology, metabolism such as accumulation of abscisic acid (ABA) and salicylic acid (SA), changes in membrane lipid composition, formation of compatible osmolytes and production of antioxidants. These processes are accompanied by notable changes in the level of various gene transcripts and proteins [16]. Our understanding of the molecular pathways in cold acclimation has changed dramatically with the discovery of the C-repeat (CRT)/dehydration-responsive element (DRE) binding transcription factors (CBF) in the model organism Arabidopsis thaliana. The CBFs bind to CRT/DRE elements present in the promoter regions of many cold- and dehydrationresponsive genes such as cold-regulated $(C O R)$ genes $[4,17]$. In these lines, over-expression of Arabidopsis $\mathrm{CBF}$ induces $C O R$ gene expression in the chilling-sensitive tomato (Lycopersicon esculentum), resulting in protection against chilling stress at $0^{\circ} \mathrm{C}$ and improved freezing tolerance [8]. These results suggest that this transcriptional regulation mechanism is conserved among several plant species. In addition, CBF type transcription factors have been found in other plants although the function remains to be evaluated. However, there are also indications of the existence of CBFindependent cold acclimaction [5]. Gene expression is regulated not only at the transcriptional level but can also be regulated by post-transcriptional events such as alternative splicing, translational and post-translational modifications like phosphorylation [2].

Whilst the molecular pathways of acclimation to low temperature are well understood for the model plant Arabidopsis [1, 16], the knowledge about the molecular basis of cold-acclimation in maize is still rudimentary. Furthermore, low temperature stress in Arabidopsis occurs at subzero temperatures while maize growth is challenged already at temperatures below $20^{\circ} \mathrm{C}$ suggesting that 
divergent acclimation pathways might be employed. In order to characterize the molecular pathways induced in maize in response to cold stress, a previous study [12-14] identified several nsovel genes, including ZmCOI6.1, whose transcript level increases after exposure to low non-freezing temperature. The aim of this study was to characterize this novel gene for a better insight into its role during cold response. We show that ZmCOI6.1 is in addition to cold also highly induced under drought and salt stress and by signalling molecules like salicylic acid and abscicic acid suggesting ZmCOI6.1 as being a conserved general stress response gene. Furthermore, the expression of ZmCOI6.1 is modified by alternative splicing in response to abiotic stress.

\section{MATERIAL AND METHODS}

\section{Plant material and growth conditions}

Maize seeds of the genotype ETH-DH7 were grown in half Hoagland solution (H2395, Sigma Chemical Co., USA) supplemented with $0.5 \%$ Fe-sequestrene, $6 \mathrm{mM} \mathrm{K}^{+}$and $4 \mathrm{mM} \mathrm{Ca}^{2+}$. Before treatment, plants were grown until the third leaf was fully developed at $25 / 22^{\circ} \mathrm{C}$ (day/night) in growth chambers (Conviron PGW36, Winnipeg, Canada) at a 12-hour photoperiod, a light intensity of $300 \mu \mathrm{mol} \mathrm{m}^{-2} \mathrm{~s}^{-1}$ and a relative humidity of 60/70\% (day/night).

\section{Reverse transcriptase (RT)-PCR, cloning and analysis of cDNA}

Total RNA was extracted from maize leaf samples using Tri Reagent according to Sigma's protocol for RNA isolation. $1.5 \mu \mathrm{g}$ total RNA of each sample was reverse transcribed to firststrand cDNAs using oligo $(\mathrm{dT})_{23}$ primer in a total volume of $20 \mu \mathrm{l}$, according to the supplier's instructions (Advantage RT-for-PCR Kits, DB Biosciences, Clontech, USA). Synthesized cDNAs were diluted in $100 \mu \mathrm{H}_{2} \mathrm{O}$ and then 4 $\mu 1$ diluted cDNAs were used as templates for PCR amplification in a volume of $20 \mu \mathrm{l}$ as follows: 25 circles at $95^{\circ} \mathrm{C}$ for $30 \mathrm{~s}, 57^{\circ} \mathrm{C}$ for 30 $\mathrm{s}$ and $72^{\circ} \mathrm{C}$ for $60 \mathrm{~s}$ and finally with an extension at $72^{\circ} \mathrm{C}$ for 5 minutes. The maize coding genes ubiquitin, ZmUBI (accession number S94466), was used as an internal standard. Amplified PCR products $(15 \mu \mathrm{l})$ were separated by electrophoresis, using $2.0 \%(\mathrm{w} / \mathrm{v})$ agarose gel, and monitored using Gel Doc 2000 (Bio-Rad Company, USA).

The cDNA from the PCR amplification was cloned into the pDrive vector (Qiagen AG, Switzerland) and transformed into E. coli DH5D cells. Clones were sequenced by MWG (MWGBiotech AG, Ebersberg, Germany).

\section{Abiotic stress and signalling molecule treatments}

Abiotic stress or signalling molecules were applied to maize plants when the third leaf was fully developed. The plants were cold-stressed by decreasing the temperature to $6^{\circ} \mathrm{C}$ or $13^{\circ} \mathrm{C}$. For the drought stress, maize plants were removed from the hydroponic culture and were left to dry in the growth chamber. The salt treatment was induced by adding $\mathrm{NaCl}$ to the Hoagland solution to obtain a concentration of $150 \mathrm{mM}$. Stress signalling molecules were applied to the hydroponic culture at a final concentration of $100 \mu \mathrm{M}$ salicylic acid (SA) or $100 \mu \mathrm{M}$ abscisic acid (ABA). All the treatments were imposed in the dark. Control plants (unstressed) were collected prior applying the selected stress treatments. The middle part of third leaves were harvested, frozen in liquid nitrogen and stored at $-80^{\circ} \mathrm{C}$ until assay.

\section{Bioinformatics}

A similarity search was performed using the basic local alignment search tool (BLAST) (National Centre for Biotechnology Information (NIH, Bethesda, MD, USA) (http://www.ncbi. nlm.nih.gov/BLAST/) and the NCBI BLAST2 service maintained by the Swiss Institute of Bioinformatics (http://au.expasy.org/tools/blast/). PLACE (http://www.dna.affrc.go.jp/PLACE/), a database of motifs found in plant cis-acting regulatory DNA elements was used to scan the promoter of the ZmCOI6.1 gene. Splicing prediction was realized using the Genscan program (http://genes.mit.edu/GENSCAN.html). Phylogenetic tree was made using the CLUSTAL W program.

\section{RESULTS}

1. A novel cold induced gene, $\mathrm{ZmCOI6.1}$ is conserved in plant species 
A previous study using the chilling tolerant maize genotype ETH-DH7 identified several novel cold-induced genes [12-14]. From this study, one gene, ZmCOI6.1, represented by four different cloned fragments was sorted out for further characterization based on the high level of occurrence in the screening. To determine the complete sequence of ZmCOI6.1, oligonucleotides, which covered the AZM4_69676 sequence from the maize genotype B73 (tgi_maize/) and which showed $96 \%$ homology with ZmCOI6.1 detected fragment, were designed to amplify this sequence, only, but not AZM4_12960 homolog sequence, which shows $81 \%$ homology with ZmCOI6.1 fragments. Overlapping regions of the corresponding gene in the ETH-DH7 genotype were amplified. The overlapping fragments were sequenced, assembled and annotated in the Genbank (accession number DQ060243) [12-14].

To investigate the possible existence of homologues and/or orthologues of the ZmCOI6.1 predicted amino acid sequence, a database search was carried out. The database analysis identified nine amino acid sequences, similar to the ZmCOI6.1 sequence: one maize homologue, two from Oriza sativa (rice) (Os03g13810 and Os10g03550 in the TIGR rice genome annotation database, http://www.tigr.org) and six from Arabidopsis thaliana (At1g20100, At1g75860, At2g17787, At3g07280, At4g35940 and At5g48610) (figure 1). ZmCOI6.1 also shares nucleotide sequence similarity with ESTs from wheat (Triticum aestivum L.), barley (Hordeum vulgare L.), sugarcane (Saccharum officinarum L.) and sorghum (Sorghum bicolor L.) (data not shown). Using the amino acid sequences, the phylogenetic relationship between sequences derived from maize, rice and Arabidopsis were analysed excluding the ESTs coding for an incomplete protein (figure 1). This analysis revealed three main groups: one consisted of ZMCOI6.1 and a maize homologue AZM4_12960 sequence together with the rice sequences, the second group accommodated the Arabidopsis sequences At4g35940, At2g17787, At3g07280 and At5g48610 and the third one At1g75860 and At1g20100. This analysis indicates that the novel cold-induced gene ZmCOI6.1 is conserved in plant species.

Gene homologues and orthologs share identity on the amino acid level where similarity in particular regions might be indicative of domains or motifs important for function. To identify putative domains, a comparison of the ten amino acid sequences mentioned above with the ZmCOI6.1 predicted protein sequence was performed and the results obtained revealed similar domains specifically at the $\mathrm{N}$ - and Cterminals (data not shown). The most conserved region was the $\mathrm{C}$-terminus with the putative motif L-P-[FY]-[TV]-V-P-F. Furthermore, a lysine-rich region was identified at the $\mathrm{N}$ terminal of all the sequences. The function of these motifs has not been described previously, suggesting that they are novel. Analysis of the amino acid sequence for transmembrane regions by TMpred [6] did not reveal the presence of transmembrane domains, thus, predicting that ZmCOI6.1 is a soluble protein. This result suggests that $\mathrm{ZmCOI6.1}$ and its maize homolog are conserved in plant species sharing high similarity at least for two domains at the amino acid level.

\section{a. ZmCOI6.1 gene is alternatively spliced}

To better understand the time course of cold induction of the ZmCOI6.1 gene, an experiment was conducted, in which seedlings were exposed to $6^{\circ} \mathrm{C}$ for 24 hours and samples were collected after one, two, four, six, 12 and 24 hours to analyze early and later response. The expression of $\mathrm{ZmCOI6.1} \mathrm{increased} \mathrm{with} \mathrm{time} \mathrm{of}$ exposure to cold confirming its regulation by cold. Upon analysis by RT-PCR, ZmCOI6.1 obtained two fragments, referred as sf1 and sf2. To determine whether the fragments sf 1 and sf 2 were indeed transcripts from the ZmCOI6.1 gene and not the expression product of another gene(s), both forms were cloned using the oligonucleotides 6551-2 and ZmCOI6.1b_R and subsequently sequenced. The sequence analysis revealed that both cDNA forms were identical with the specific parts of the ZmCOI6.1 gene (data not shown).At normal growth condition (non-stress condition), both fragments sf 1 and sf 2 have 3 exons and 2 introns. Under stress treatments, the intron I1 is splice out in sf 1 and the intron 2 in both sf 1 and sf 2 (figure 2). 


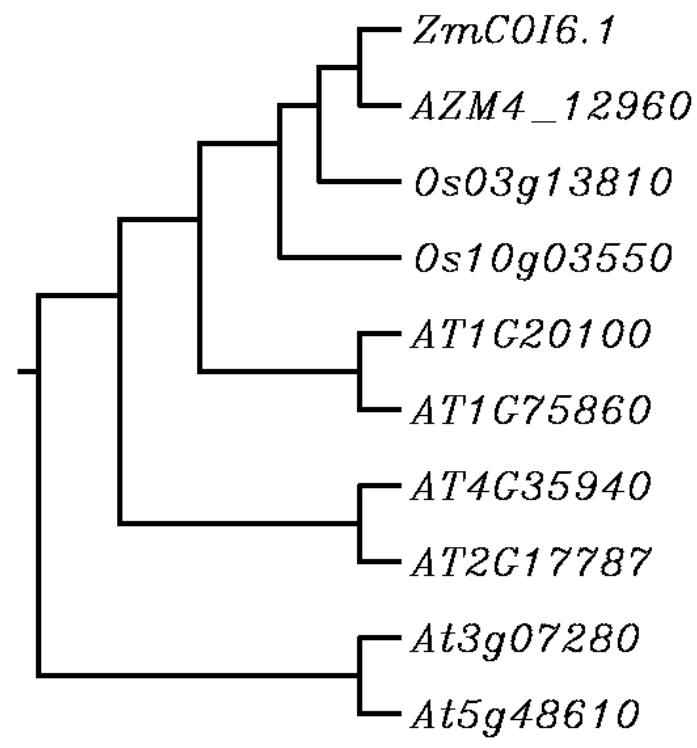

Figure 1. ZmCOI6.1 is conserved in plants as shown by phylogenetic analysis of the deduced ZmCOI6.1 amino acid sequence, homolog and ortholog sequences. The phylogenetic tree of the amino acid sequences of ZmCOI6.1, maize homologue and orthologues in rice and Arabidopsis were constructed using the CLUSTAL W program

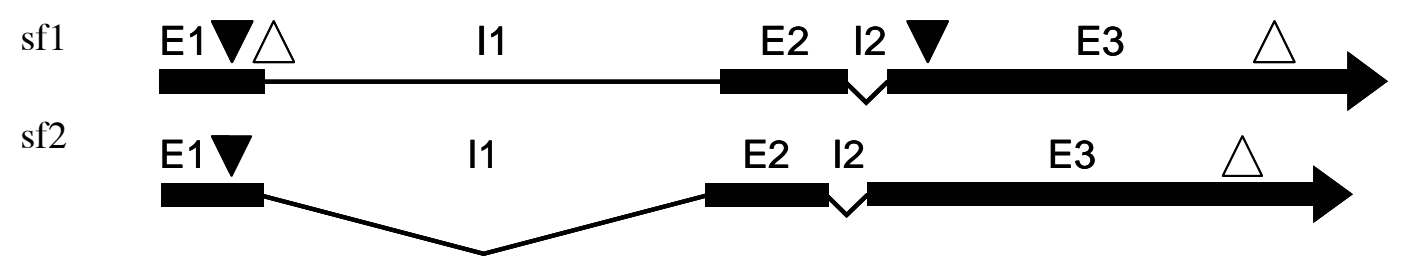

Figure 2. The splicing structure of ZmCOI6.1 to yield sf1 and sf2, as predicted from gene analysis. Thick lines represent exons (E1, E2 and E3) and thin lines introns I1 (nucleotide position from 744 and 1866) and I2 (nucleotide position from 2180 and 2280). Angled lines represent fragments spliced out to yield sf1 and sf 2 respectively. Triangles indicate the position of the start $(\boldsymbol{\nabla})$ and stop $(\triangle)$ codon. The predicted alternative splicing transcripts are sf1 containing E1, I1, E2 and E3 and sf2 containing E1, E2 and E3

Interestingly, we found that sf 1 and sf 2 were amplified from the samples taken at 0 hour (control) as well as under cold treatment (figure 3). A lower level of sf1 was found under control conditions, but the levels increased with the length of time exposed to cold stress. The smaller cDNA fragment, sf 2 , decreased during exposure to $6^{\circ} \mathrm{C}$ from 1 to 12 hours but started to increase at 24 hours. To test the effect of suboptimal temperature $13^{\circ} \mathrm{C}$ on the expression of ZmCOI6.1 and the expression of the two fragments, the similar experimental set-up at $13^{\circ} \mathrm{C}$. The data shown that, at $13^{\circ} \mathrm{C}$ treatment, the sf 2 transcript was also present and remained stable over time, while the levels of sf 1 increased rapidly (figure 3 ). These results show that $\mathrm{ZmCOI6.1}$ is induced at short exposure to cold and increases with time. The RT-PCR suggests that the expression is characterized by the appearance of two fragments.

The presence of two fragments in the analysis of $\mathrm{ZmCOI6.1} \mathrm{expression} \mathrm{pointed} \mathrm{to} \mathrm{the}$ possibility that alternative splicing is taking place. Analysis of the putative spliced forms of 
ZmCOI6.1, sf1 and sf2, revealed that sf1 expanded from nucleotide 640 to nucleotide 3196 with 101 nucleotides missing between the positions 2179 and 2281 (I2) (Figure 3). In the sf2 transcript, the regions between 744 and 1867 (I1) and between 2179 and 2281 were missing.

To identify the positions of the introns and exons as well as the splicing points, the ZmCOI6.1 sequence was analyzed to determine the splicing consensus sequence, AG/GTAAGT, of the introns 5'-splice donor site and TGCAG/G of the 3'-splice acceptor site as well as the consensus branch point region CURAY (R, purine; Y, pyrimidine) [9]. Both the first and second introns had a conserved 5'-splice donor site. However, the 3'-acceptor site was conserved in the second intron but less conserved in the first. The branch point sequence was well conserved in the first intron but was less obvious in the second. For further analysis of the gene, the splicing predictor GENSCAN program [3] was used to verify the results described above. This program predicted the donor sites of the first and second introns, the acceptor site of the second intron as well as the branch point region of the second intron but not of the first one. Other splicing regions in the first intron were predicted by GENSCAN, which corresponded neither to the two spliced forms found in this study nor to any of the other expressed sequence tags (EST) in the database (data not shown). Similar pattern where also found in the sequence of rice and Arabidopsis (data not shown). These results show that ZmCOI6.1 sequence harbours conserved splicing points that would give potential products of sizes that are in agreement with sf 1 and sf2 obtained in the RT-PCR analysis.

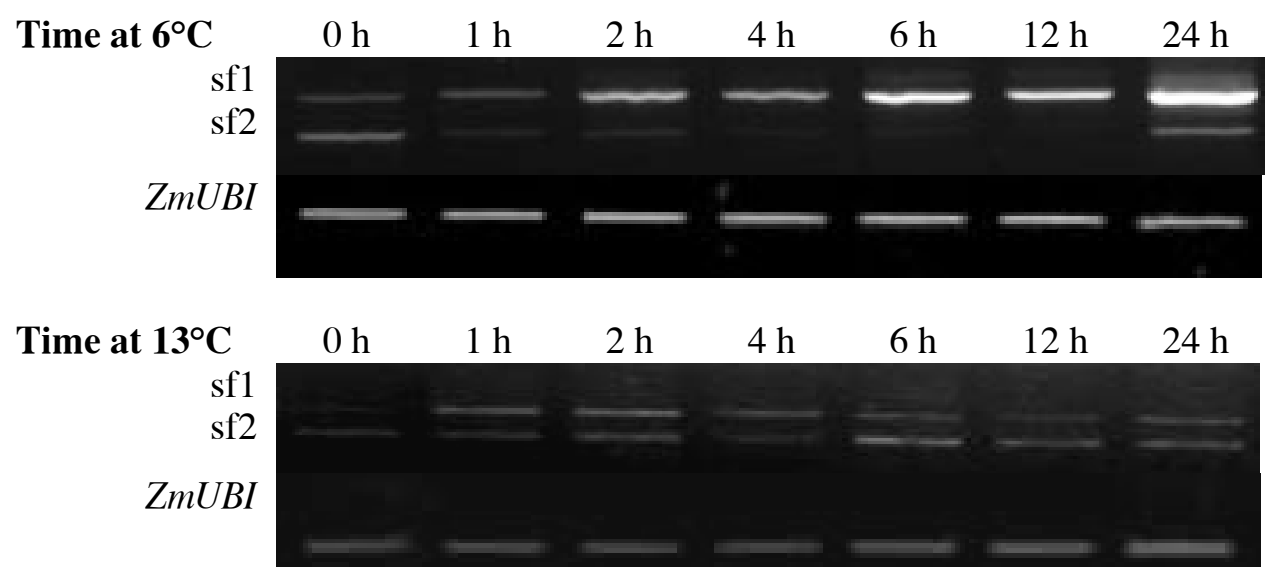

Figure 3. Expression of ZmCOI6.1 gene under abiotic stresses: ZmCOI6.1 is induced by cold, expression increases with time of exposure and is alternatively spliced. The effect of low $\left(6^{\circ} \mathrm{C}\right)$ and suboptimal $\left(13^{\circ} \mathrm{C}\right)$ temperature (in the dark) on the expression and alternative splicing of the ZmCOI6.1 gene was examined. 0 hour indicates samples taken prior to treatment. RT-PCR was performed with the primers $6551-2$ and ZmCOI6.1b_R to analyse the expression of the ZmCOI6.1 transcripts. ZmUBI was used as the internal control.

2. ZmCOI6.1 gene alternative splicing occurred under different abiotic stresses and signalling molecules

In a previous study the expression of ZmCOI6.1 was changed in response to different abiotic stresses [12]. The question arose whether the alternative splicing occurs in the same way under other abiotic stresses or after treatment with signalling molecules as it did under cold stress. Therefore, the induction of the ZmCOI6.I gene was tested for drought and salt stress and with signalling molecules known to induce stress responses, for example to abscisic acid (ABA) and salicylic acid (SA). The ZmCOI6.1 gene transcript accumulated under drought and under salt stress as well as after treatment with SA and ABA. The strongest induction was obtained during drought and during the $\mathrm{ABA}$ treatment, where the sf 1 transcript increased but 
sf2 remained at low levels (figure 4). Under sodium chloride and jasmonic acid treatment the expression of the sf 2 transcript was suppressed (figure 4 and data not shown).
These results show the conservation of alternative splicing of ZmCOI6.1 gene in response to abiotic stress other then cold and induction by signaling molecules.

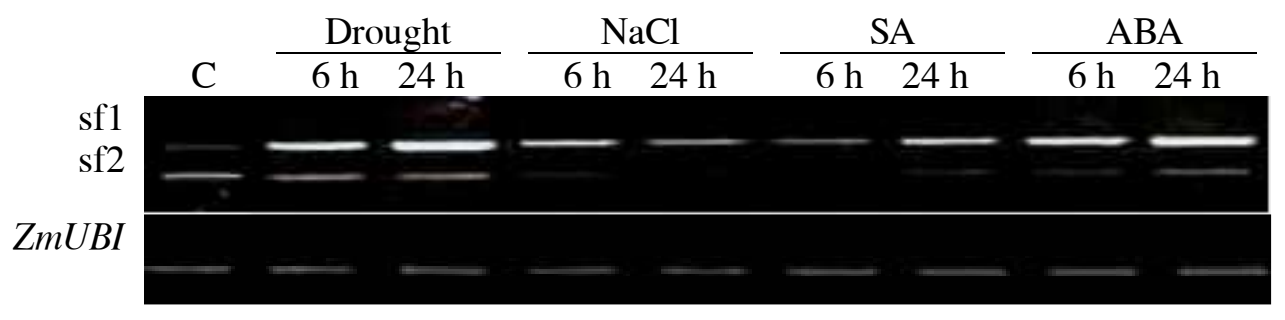

Figure 4. Expression of fragment $\mathrm{sf} 1$ of ZmCOI6.1 gene: $\mathrm{sf} 1$ is increased in maize leaves (ETHDH7) in response to various stress treatments (drought, NaC,SA and ABA). RT-PCR was performed with cDNA produced from RNA extracted from maize seedlings at 0 hour of treatment at $25^{\circ} \mathrm{C}$ and after 6 and 24 hours of exposure of maize seedlings to stresses. Ubiquitin (ZmUBI) was used as the internal control.

\section{The ZmCOI6.1 gene promoter contains predicted conserved stress cis-acting elements}

Genes that are induced by stress or other treatments usually harbour short sequences, cisacting elements, within the promoter that are identified by transcription factor, thereby regulating gene expression. To analyze the ZmCOI6.1 promoter cis-acting elements, the search was performed in a database using the PLACE program (PLACE/). Several cis-acting elements were identified in the ZmCOI6.1 promoter, including the low temperatureresponsive elements MYC, DRE/CRT-core,
DRE/CRT-HvCBF2, LTRE-core and LTRE-1. Other cis-acting elements were identified, which are involved in abiotic and biotic stress: MYB1, ABRE-like G-box, MYB-core and ASF1 (Figure 5; Table 1). Some of these cis-acting elements were also present in some of the promoters of the orthologs of ZmCOI6.1 suggesting that they share a common feature of possible transcriptional regulation (data not shown). This result shows the presence of cis-acting element motifs in the promoter of ZmCOI6.1 and the complexity regulation of ZMCOI6.1 gene expression upon induction by different abiotic stresses.

\section{DISCUSSION}

1 cgctgtgtcgcctagaaatagcgatgtggtacattccgcaccgcacatcgtcacgacggacgcgccttac

71 ccggcttgcgctggcaacgcgacc cacgtgccggtccgtgattgcgggttgccgac gcttctaggtcggt

MYClG-box/ABRE-like DRE/CRT-core/LTRE-core

141 tccgggtcgtgggecctcatacacgttgcgtgcgecccgggaacactcaagtactcaaccceggctccga ACGT

211 agtccgactgcaagcggggcccacacgctcttaacctagctgcaccegcgacgcgtagttgcagcgcatc LTRE-core

281 gccattcacagcaccegcatataggtetgttgcactgacatggcgtcceaccacgggectgtgcc caact

$$
\text { MYB-core MYC|MYB2 }
$$

351 gtcagtgaattcgttccggaaacaacgcgtaaccgagactgacgcgctagttgccegcacgactcggcct

DRE1-Rab17 ASF1

421 cetcgeccccggetttaaatagtggcgtacccccatcccatagaagagactctttcatttecttctaccg Predicted core Promoter INR

491 cagcctcagaattccecctccccegtagcgaaacctagccgecacgeca aaaccaaatcccgecgagc AGC-box|GCC-core MYB1|REalpha 
561 ccgaaattttceggcgggttccttgccgcgaatcgattgatttcgagcgattcgactcctttgtgatctc LTRE-1|HSE-like

631 tcggcggggtagagcgcggtcgaccgtcggccatgtcgaggtgcttccctaccegccaccggggtacgt

DRE/CRT-HvCBF2 ABRE-like/ACGT

701 geggaacccagtggecgtggccgagccggagtcgaccgctaaggtttgttgaaccttcggatttaca DRE/CRT-HvCBF2

Figure 5. ZmCOI6.1 promoter contains motifs of conserved cis-acting elements involved in stress. The scheme of the ZmCOI6.1 promoter region and the 5'-end of the transcript showing predicted position of stress-responsive cis-acting elements motifs (for details see Table 1). The sequence is numbered according to the sequence (DQ060243). A hyphen denotes the absence of the corresponding nucleotides residues. The predicted translational start codon is bold and in italics. Capital letters indicate transcribed regions and lower case letters are non-transcribed regions.

Table 1

Stress-responsive cis-acting elements present in the $\mathrm{ZmCOI6.1}$ promoter region (see Figure 5), the abiotic/biotic stresses, in which they are involved and the conserved sequences. ${ }^{1}$ as-1-like elements are characterized by two imperfect TGACGTCA motifs, separated by 4 bp, ${ }^{2} 11$-bp ethylene-responsive element, TAAGAGCCGCC, ${ }^{3} \mathrm{G}$-box is 5 '-C/AACACGTGGCA-3' with a CACGTG hexanucleotide core.

${ }^{4} K=\mathbf{G}$ or $\mathbf{T} ; \mathbf{N}=\mathbf{A}, \mathbf{C}, \mathbf{G}$ or $\mathbf{T} ; \mathbf{R}=\mathbf{A}$ or $\mathbf{G} ; \mathbf{W}=\mathbf{A}$ or $\mathbf{T} ; \mathbf{Y}=\mathbf{C}$ or $\mathbf{T}$

\begin{tabular}{|l|l|l|}
\hline \multicolumn{1}{|c|}{ cis-acting element } & \multicolumn{1}{|c|}{ Involvement } & \multicolumn{1}{|c|}{$\begin{array}{c}\text { Recognition } \\
\text { Sequence }\end{array}$} \\
\hline MYC & Drought (ABA), cold & CANNTG \\
\hline MYB-core & Drought stress & CNGTTR \\
\hline MYB1 & Dehydration stress (ABA) & WAACCA \\
\hline MYB2 & Dehydration stress (ABA) & YAACKG \\
\hline \hline ABRE-like & Drought (etiolation) & ACGTG \\
\hline DRE/CRT-core & Cold- and dehydration-responsive expression & TACCGAC \\
\hline DRE/CRT-HvCBF2 & Low temperature & GTCGAC \\
\hline DRE1-Rab17 & Drought (ABA) & ACCGAGA \\
\hline LTRE-core & Low temperature & CCGAC \\
\hline LTRE-1 & Low temperature & CCGAAA \\
\hline \hline ASF1 1 & Auxin and/or salicylic acid; perhaps light regulation & TGACG \\
\hline INR & Light-responsive & YTCANTYY \\
\hline AGC-box, GCC-box & Ethylene (=ethylene-inducible defense genes) & AGCCGCC \\
\hline GCC-core & Defense, jasmonate & GCCGCC \\
\hline ACGT & Drought (etiolation) & ACGT \\
\hline G-box & Pathogen, ABA, light & CACGTG ${ }^{3}$ \\
\hline Realpha & Etiolation & AACCAA \\
\hline HSE-like & Heat shock, pathogen & $\begin{array}{l}\text { CNNGAANNNTTC } \\
\text { NNG }\end{array}$ \\
\hline
\end{tabular}


In order to get more insight into the response of maize to low temperature, we have characterized a novel cold-induced gene ZmCOI6.1. The sequence analysis reveals $\mathrm{ZmCOI6.1} \mathrm{is} \mathrm{a} \mathrm{conserved} \mathrm{gene} \mathrm{in} \mathrm{plants} \mathrm{showing}$ high similarity to sequences from rice and Arabidopsis and also to ESTs from wheat (Triticum aestivum L.), barley (Hordeum vulgare L.), sugarcane (Saccharum officinarum L.) and sorghum (Sorghum bicolor L.). The deduced amino acid sequence indicates that these proteins are possibly soluble and they share several motifs of high identity whose function still remains to be characterized. Although preliminary results show that ZmCOI6.1 homolog is induced by cold stress it remains to be investigated for response to other stresses [12].

The ZmCOI6.1 gene is induced by several abiotic stresses and signaling molecules indicating that the ZmCOI6.1 is probably a general stress-regulated gene. This is also supported by the fact that its promoter contains several cis-acting elements, suggesting possible regulation by different transcription factors.

The presence of regulative modules within the promoter is common in stress-induced genes $[1,16]$. These elements overlap in function with regard to induction in response to stress, as exemplified by the promoter induction of the drought-induced gene RAB17 [7]. However, it remains to be determined whether all the predicted cis-acting elements are important for the regulation of ZmCOI6.1 gene expression; the induction by different environmental stress point in this direction. The increased expression of $\mathrm{ZmCOI6.1} \mathrm{upon} \mathrm{treatment} \mathrm{with} \mathrm{ABA} \mathrm{and} \mathrm{SA}$ suggests that ZmCOI6.1 acts downstream of the effector pathways of these signaling molecules.

The results of this study show that the ZmCOI6.1 gene expression is characterized by alternative splicing producing two transcripts, sf1 and sf2. Alternative splicing, also known as differential splicing, is a conserved mechanism regulating a large part of the expression of many genes [8]. The modules in ZmCOI6.1 that are involved in splicing were identified by comparing its sequence with conserved splicing motifs and by means of the GENSCAN program, which corroborated the intron retention mechanism. The splicing sites within
ZmCOI6.1 are all classical sites, with the exception of that at the splice acceptor site in intron 1 (I1). The I1 of sf 1 contains several stop codons, making it a non-translated transcript, although it cannot be ruled out that translation takes place by avoiding the Il intron code region by means of an unconventional mechanism as for example ribosomal shunting or internal initiation. Assuming that translation starts at the same position in sf1 as in sf 2 , the deduced amino acid sequence of sf 1 would be only 29 amino acids long due to a stop codon at the beginning of exon 1. Start of translation at the ATG in position 2376 (I3) would result in a 285 amino acids long protein which would share the C-terminus of sf2 (figure 2). This analysis suggests sf1 as non-functional transcript.

The predicted sites for alternative splicing were also present in the sequence of rice, as shown by the alternative splicing form from the locus Os03g13810 (TIGR, rice genome annotation database) suggesting that the orthologs are not only similar on the amino acid level but as well share the same alternative splicing modification. As in the ZmCOI6.1 gene, two mRNA forms are produced from Os $03 \mathrm{~g} 13810$, where the first intron is retained in the larger one and the second intron is spliced out in both of them (unpublished).

The balance between $\mathrm{sf} 1$ and $\mathrm{sf} 2$ of ZmCOI6.1 was affected by the low temperature and being more stable at $13^{\circ} \mathrm{C}$ than at $6^{\circ} \mathrm{C}$; at $6^{\circ} \mathrm{C}$ there is more sf 1 than sf 2 . This difference in the transcript level at $6^{\circ} \mathrm{C}$ and $13^{\circ} \mathrm{C}$ suggests that alternative splicing might play an important role in the regulation of ZmCOI6.1 expression depending on the strength of the low temperature stress. It is possible that $\mathrm{sf} 2$ is necessary for normal growth of the plant acting, probably as a negative regulator of the stress response. These results are supported by preliminary results showing that a T-DNA insertion in the Arabidopsis heterolog of ZmCOI6.1 gene (At4G35940) is more tolerant than wilt type plants to cold, drought and salt stress (results not shown). Under a strong cold stress $\left(6^{\circ} \mathrm{C}\right)$ sf2 was down-regulated or remained constant. Therefore, to compensate for induction of the gene through the cis-acting elements in the promoter, alternative splicing 
would be favoured to produce a transcript, sf1, which is probably non-functional. On the other hand, at $13^{\circ} \mathrm{C}$ the function of $\mathrm{ZmCOI6.1}$ would be more important; alternative splicing would be balanced towards the "functional" transcript sf 2 as shown by its increase at $13^{\circ} \mathrm{C}$ in contrast to $6^{\circ} \mathrm{C}$. This would be a link to its possible role as a negative regulator. The fact that the sf 2 transcript also accumulates in response to signalling molecules, such as abscisid acid and salicylic acid indicates that sf1 probably regulates the expression of the ZmCOI6.1 gene and is not an artifact of the abiotic stresses. It is important to mention that $\mathrm{I} 2$ is spliced out in both, sf 1 and sf 2 transcripts; this indicates the specifity of intron retention when plants are exposed to adverse conditions or to signalling molecules. The retention of unspliced introns in a fraction of the transcripts seems to be common in plants and could either reflect low efficiency of splicing or a regulatory process [9]. In support of the later it was found in Arabidopsis that a high fraction of the alternatively spliced forms were retained introns [11]. Interestingly, the transcripts with retained introns were for the most part transcripts of stress and external/internal stimuli-related genes. An intron retention mechanism has been described recently for cold-regulated genes in durum wheat. In this study, genes coding for a putative ribokinase and a $\mathrm{C} 3 \mathrm{H} 2 \mathrm{C} 3 \mathrm{RING}$-finger protein were characterized by the stress-induced retention of a subset of introns in the mature mRNA [10].

It remains to be characterized how alternative splicing regulates the activity of ZmCOI6.1 but most importantly how ZmCOI6.1 regulates the stress response in maize.

\section{REFERENCE}

1. Abe H. et al., 2003: Plant Cell, 15: 63-78.
2. Bade J. et al., 2003: Plant Molecular Biology, 52: 53-68.

3. Burge C., Karlin S., 1997: Journal of Molecular Biology, 268: 78-94.

4. Chinnusamy V., Zhu J., Zhu J. K., 2007: Trends in Plant Science, 12(10): 444-451.

5. Dubouzet J. G. et al., 2003: Plant Journal, 33: 751-63.

6. Hofmann K., Stoffel W., 1993: Biol. Chem. Hoppe-Seyler, 374: 166.

7. Kizis D and Pages M., 2002: Plant Journal, 30: 679-689.

8. Lee J. T. et al., 2003: Plant Cell and Environment, 26: 1181-1190.

9. Lorkovic Z. J. et al., 2000: Trends Plant Science, 5: 160-167.

10. Mastrangelo A. M. et al., 2005: Planta, 221: 705-715.

11. Ner-Gaon H. et al., 2004: The Plant Journal, 39: 877-885.

12. Nguyen Thuy Ha et al., 2008: Journal of Biology, 30(2): 77-87.

13. Nguyen H. T. et al., 2009: Plant Physiol. Biochem., 47: 116-122.

14. Orlene Guerra-Peraza, Ha Thuy Nguyen, Peter Stamp, Jörg Leipner, 2009: Plant Science, 176: 783-791

15. Vannini C. et al., 2004: Plant Journal, 37: 115-127.

16. Thomashow M. F., 1999: Annual Review of Plant Physiology \& Plant Molecular Biology, 50: 571-599.

17. Zhang F. L. et al., 2008: Plant Science, 174: $510-518$. 


\title{
PHẦN III: NGHIÊN CÚU VAI TRÒ CỦA CÁC GIEN LIÊN QUAN ĐẾN KHẢ NĂNG CHỐNG CHİU LẠNH Ở NGÔ: QUÁ TRİNH BIỂU HIỆN VÀ TRİNH TỬ VÙNG PROMOTER CỦA CÁC GIEN NÀY
}

\author{
NGUYỄN THÚY HÀ, JÖRG LEIPNER, \\ ORLENE GUERRA-PERAZA, PETER STAMP
}

\begin{abstract}
TÓM TÁ́T
Bằng kỹ thuật PCR-cDNA Select Subtraction (hay còn có tên goi khác là SSH- Suppression Subtractive Hybridization) chúng tôi đã phân lập được 18 gien có biểu hiện cao trong điều kiện lạnh $6^{\circ} \mathrm{C}$ và $13^{\circ} \mathrm{C}$. Trong số 18 gien này, gien ZmCOI6.1 có tần số xuất hiện rất cao $(49 \%)$ trong thư viện cDNA. Qua phân tích sản phẩm RT- PCR cho thấy gien ZmCOI6.1 có biểu hiện cao không những trong điều kiện nhiệt độ thấp mà còn có phản ứng với các tác nhân khác như khô hạn, muối mặn và các phân tử truyền tín hiệu stress như $\mathrm{ABA}$ và SA nhu vậy có thể khẳng định $Z m C O I 6.1$ có vai trò của gien chịu trách nhiệm phản ứng lại khi gặp điều kiện sống bất lợi. Kết quả phân tích cho thấy, sự biểu hiện của gien ZmCOI6.1 do 2 yếu tố phiên mã quy định. Ngoài ra, qua phân tích vùng promoter của gien này cho thấy, gien có chứa nhiều yếu tố chịu trách nhiệm phản ứng lại khi gặp điều kiện sống bất lợi giống như ở gen lúa và Arabidopsis.
\end{abstract}

Ngày nhận bài: 20-4-2008 